\title{
The Impact of Corona-Virus Pandemic Effected the Air Pollution in India
}

\author{
Shubham Chugh ${ }^{\text {a }}$, Ravi Kaushal ${ }^{\text {b }}$, and Sahil Kohli ${ }^{\mathrm{c}}$ \\ University School of Business-Industry Collaborated Program, Chandigarh University, Mohali, Punjab
}

Article History: Received: 11 January 2021; Accepted: 27 February 2021; Published online: 5 April 2021

\begin{abstract}
In a country like India, where the major decease are been caused because of the Air pollution, which has affected around 4 million lives because of this pollution only, the cause of the rise in Air pollution is not only from the factories but also the vehicles which use to run on the streets as corona-virus can stay in the air for around 30 minutes, which can cause problems to millions of lives moving on the street, mostly the poor. In India air pollution has rated to almost least in the past 20 years which has contributed to the break from spreading.In India, Delhi and other most populated states stated a drastic downfall in Air pollution with about 60 percent decline in air pollution of PM - 2.5 particularly known as "fine particulate matters" in Delhi when compared with 2019 while the pollution control in other countries couldn't see much change and which has also seen a rise in corona-virus cases.In this paper we have analyzed the impact of rising in the number of the corona-virus cases concerning the most polluted cities to state the actual scenario that is air pollution leads to a rise in a pandemic situation. This paper is primarily based on secondary sources of data collection including the state-wise downfall in the level of air pollution, impact on the environment from the deadly disease i.e. Corona-virus, prospects, impact on the health of the individual.
\end{abstract}

Keywords: Air Quality Index (AQI), Nitrogen Dioxide (NO2), P.M. 2.5, Municipal

Corporations (MCs), Air Polluted Cities, Death Rate from Air Pollution, CoVID-19 Pandemic

\section{Introduction}

India is ranked among 21st position out of the top 30th Countries which have recorded the most air pollutant Countries in the world. This situation is not the same when compared to India before and after Lockdown.Air pollution is a major environmental risk to health. By reducing air pollution levels, countries can reduce the burden of disease from stroke, heart disease, lung cancer, and both chronic and acute respiratory diseases, including asthma as mentioned in (www.who.int).

As per the WHO (World Health Organization) details, India was almost double or triple in some cities from the set average Air Quality Index which is next to unhealthy and affecting the Human health, A statement also seemed to show that, total deaths in India every year from the Air pollution was affecting almost 2 million lives, which is very dangerous as due to the level of P.M-2.5 and due to Nitrogen Dioxide in the air was almost double from the average level set by the WHO. But this above changed altogether, as on March, 22 when our Prime Minister decided to have "Janta Curfew" to fight back from the Corona-virus Pandemic, thus helped India to reach at Air Quality Index to which was set up by WHO a record which India wasn't even able to achieve in its past 20 years.

Due to Corona-virus Pandemic, this has lead to self-locked by 1.3 Billion individual in their homes i.e. self Quarantine, all the factories to stop working, no production, no manufacturing, this has lead to very positive feedback as not only the Air Quality is improved but also the environment also seems healthy, "Ganga River" the longest river in India which is covering in almost 1600 miles, also seems to be the clearest. As written in

(https://science.thewire.in/environment/ganga-river-lockdown-cleaner-namami-gange-sewage-treatmentecological-flow/).

In India among the total of 103 cities, of which 23 cities were recorded "good "air quality index and the remaining 65 cities were recorded "Satisfactory" air quality Index. As per the Air Quality Index Report,

It states that

1. Between 0-50 index is considered to be good.

2. Between 51-100 indexes, it is considered to be satisfactory.

3. Between 101-200 indexes, it is considered to be moderate.

4. Between 201-300 indexes, it is considered to be poor.

5. Between 301-400 indexes, it is considered to be very poor.

6. Between 401-500 indexes, it is considered to be Severe.

Due to the Corona-virus Pandemic, it has ensured that almost every activity is halted which has lead to a much cleaner environment, but this situation will get worst in an upcoming couple of months after this Pandemic situation. 
As on March, 25 which is considered to be the first day of lockdown in India the average of PM-2.5 level seen a steady decline of about 22 percent and the other one is Nitrogen Dioxide which comes from smoldering the fossil fuels was dropped by around 15 percent. Not only this can the people easily be able to see the hills from their home roofs.

But this also doesn't mean that India is doing well by showing the reduction in Air Pollution, this Corona-virus has to lead to almost 50,000 lives affected due to this Pandemic and of which 1700 have died so far as per the data received on May, 6 as stated in report published in www.corona.mygov.in

In this paper, we have mentioned all the major cities and their Air Quality Index along with Pm-2.5 and Nitrogen Dioxide gas which causes death to the human lives.

\section{Review of literature}

In relation to the paper Impact of Corona-virus on air pollution, here are some of the authors' reviews as discussed in relation to impact of air pollution in India, (Van Der Hoek et al., 2004)discussed the impact of total suspended particulates in the air and the quality improvements introduced by the 1970s (CAAA) Clean Air Act Amendments Act, has declared the impact of death caused due to only air pollution. (Chay\& Greenstone, 2011) find that the Air and water pollution and in relation to the infant mortality rate, while discussing the paper, the author also discussed the benefits of environmental regulations t-test, f-test are been used while describing the data level of Nitrogen Dioxide present in the air. (Leveson, 1989) examined the impact of air pollution on the lives of individuals living in Delhi and discussed the findings that the death rate and the age of death are very different when compared with the USA as the death of an individual starts after the age of 65 years but here in India, it is completely opposite as in India which is mostly before the age of 65 years because of only air pollution in India. (Ismail \& Ahmed, 2018) using surveys to measure the air quality impact on the individuals who are living in Delhi, Chi-square test is been used while understanding the impact, cross-tabulation was also used while analyzing both primary and secondary source of data is been used and calculated and revealed the vehicle emission is the main source of the rise in pollution. (Bukhari \& Jameel, 2020) examined the impact of Corona-virus worldwide and the contribution of World Health Organization along with the air quality level is been considered while analyzing, and stated, air quality is also affecting the earth and also mentioned the testing kits which are been used for the speedy recovery of the CoVID-19 patents. A secondary source of data is been taken into consideration. (Khot\&Nadkar, 2020) analyzed the threat of CoVID-19, explained poor prognostic factor, "MuLBSTA score", the diagnosis was based on PCR based testing of proper respiratory illustrations. Ways to follow a standard for infection control measures and stated the importance of coordination, worldwide in order to achieve from the situation.

\section{Objective}

1. To enumerate the impact of CoVid-19 Air pollution.

2. To find which state is performing at which Air Quality Index (AQI)

3. To understand the death caused in India due to Air pollution.

4. To understand the various measures to be followed by the country in a post lockdown situation.

\section{Research Methodology}

This paper is primarily based on secondary sources of data collection, all the foremost cities and states are been covered for describing the Air Quality Index issue, PM - 2.5, Nitrogen Dioxide, etc. Air Quality Index (AQI) is an index for measuring the air quality in India, a rage is been set for measuring the quality i.e.

Air Quality Index

\begin{tabular}{|c|l|l|}
\hline \multicolumn{2}{|c|}{ Air Quality Index (AQI) } \\
\hline \hline AQI & Observations & Impact on health \\
\hline $0-50$ & Good & Less or hardly any impact \\
\hline $51-100$ & Satisfactory & Minor breathing problem to sensitive people \\
\hline $101-200$ & Moderate & Breathing discomfort to people with lungs, Asthma or heart problems \\
\hline $201-300$ & Poor & Breathing discomfort to people on prolong exposure \\
\hline $301-400$ & Very Poor & Respiratory problem/illness on prolong exposure \\
\hline $401-500$ & Severe & Affects healthy people and seriously impacts those with already existing problem \\
\hline
\end{tabular}

PM - 2.5 as stated, is a fine particulate matter (PM2.5) is an air pollutant that is a concern for people's health when levels in the air are high. PM2.5 is tiny particles in the air that reduce visibility and cause the air to appear hazy when levels are elevated, as said in www.lung.org.

Air Quality Index is considered among top 4 highly polluted cities of India, the data above shown is dated 03/05/2020, which shows: 


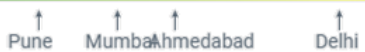
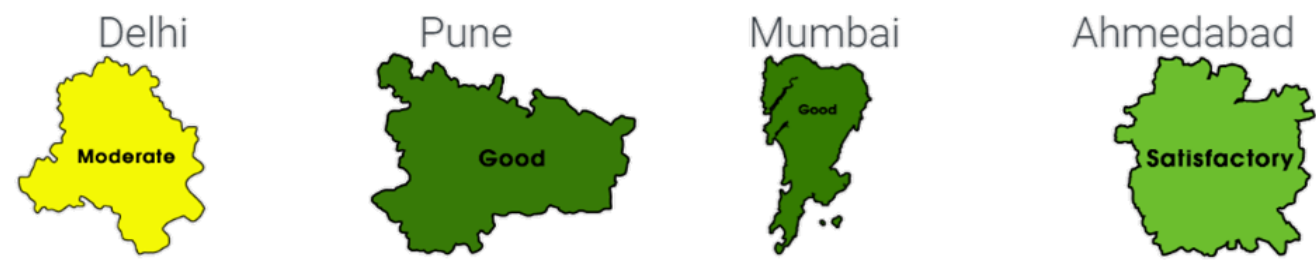

From the above bar line, it is showing the major polluted cities are on the scale between 0 to 100 range where India wasn't able to achieve from the past 20 years:

1. Delhi is coming in moderate range as covering fewer than 101 to 200 indexes.

2. Pune is coming in Good range as covering the range between 1-50 indexes.

3. Mumbai is coming in good range only as it is covering the range between 51-100 indexes.

4. Ahmadabad is coming in a satisfactory range as it is covering the range between 51-100 indexes.

After the lockdown i.e. from 22nd March 2020 India has seen the cleaner and much healthy environment which hasn't been seen before in the past twenty years. This Corona-virus has to lead to cleaner air and a healthy environment not only in India but almost around the globe thus showing a positive impact on air pollution, and the life of individuals as a whole.

Graph showing the average concentration of Nitrogen Dioxide in Air, in different states of different countries:

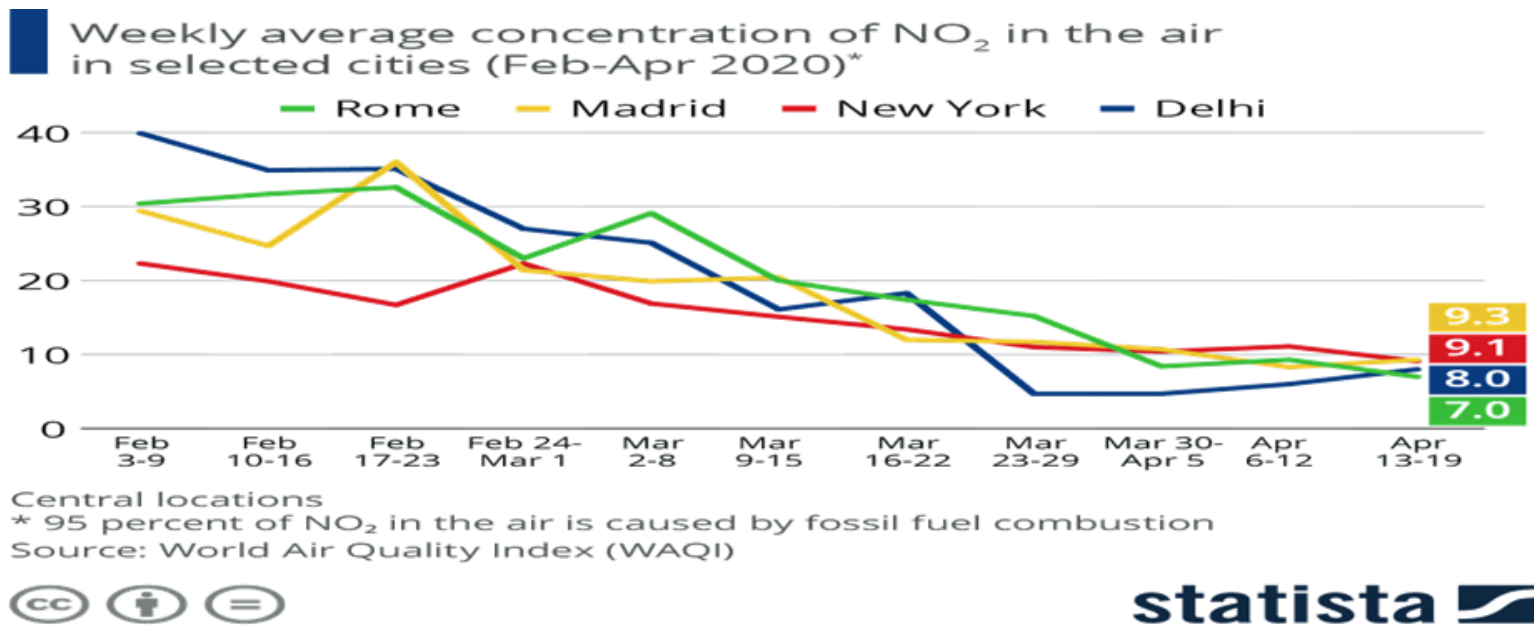

From the above graph taken from www.statsta.com, it is clear from the fact that it is covering pre and post lockdown period across the world, few major polluted cities are been covered in analyzing the air pollution level:

1. Before lockdown, Delhi (India) was one of the most pollutant city with almost 40 percent of the level of Nitrogen Dioxide (NO2) and during lockdown period this percentage of Nitrogen Dioxide level has reduced to just 8.0 percent.

2. Before lockdown, New York (USA) was one of the 2nd most pollutant city with almost 22 percent of the level of Nitrogen Dioxide (NO2) and during lockdown period this percentage of Nitrogen Dioxide level has reduced to just 9.1 percent.

3. Before lockdown, Madrid (Spain) was one of the 3rd most pollutant city with almost 30 percent of the level of Nitrogen Dioxide (NO2) and during lockdown period this percentage of Nitrogen Dioxide level has reduced to just 9.3 percent.

4. Before lockdown, Rome (Italy) was one of the 4th most pollutant city with almost 30 percent of the level of Nitrogen Dioxide (NO2) and during lockdown period this percentage of Nitrogen Dioxide level has reduced to just 7.0 percent. 
95 percent of Nitrogen Dioxide (NO2) is caused due to burning of fossil fuel/combustion. Thus this Nitrogen Dioxide has affected most of the lives, like the burning of fossil fuel, which is not healthy and not even hygienic.Nitrogen dioxide, or NO2, is a gaseous air pollutant composed of nitrogen and oxygen and is one of a group of related gases called nitrogen oxides, or NOx. NO2 forms when fossil fuels such as coal, oil, gas, or diesel are burned at high temperatures, as said in www.lung.org.

Not only this, Air pollution causes lots of problems, this doesn't mean that the problem should be visible but it can be fatal in nature including

1. The air pollution has caused 29 percent of death from Lung Cancer

2. 24 percent of the total death is been caused due to stroke caused by air pollution

3. The total of 25 percent of death is been caused by a Heart infection

4. Maximum individual faces problem because of air pollution is of Lung disease which comprising of 43 percent of the total.

Below is the graph describing the health risk which an Individual features from various undecidedactivities?

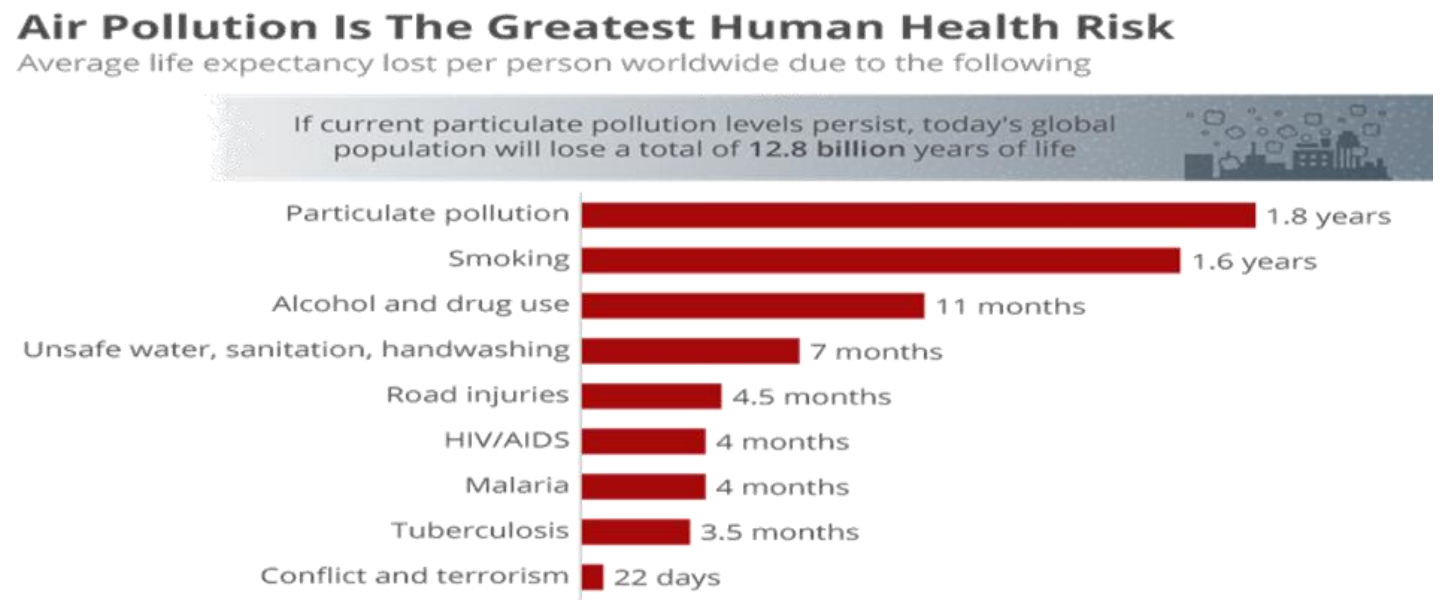

statista 5

It is clear from the fact that in www.statista.com

1. The most affected source of an individual's life expectancy is the Particulate pollution, which includes Nitrogen Dioxide, PM-2.5 Affected in a total of about 1.8 years which is far more than even consuming a cigarette or any alcohol or drugs.

2. The second most affecting the human life expectancy is smoking and Alcohol and Drug usage i.e. 1.6 years and 11 months comparatively.

3. HIV/AIDs and Malaria have affected the life expectancy to around 4 months, then comes tuberculosis which has affected the life expectancy on an average of 3.5 months and with the least 22 days affecting the conflict and terrorism.

But with the Corona-virus Pandemic, this has affected the life of the individual in a very positive way, as this lockdown has quarantine 130 crore individuals inside their homes, no movement of vehicles as everything is parked at their places, no factory is working, which has lead to an improvement in health quality, thereby helping individuals to inhale much pure and healthy air, even this has also been noticed that India achieved its average Air Quality index after twenty years stated in www.ecowatch.com.

Below table is describing the details of four major populated cities with relation to the percentage reduction in PM- 2.5 and Nitrogen Dioxide

\begin{tabular}{lrr} 
City & PM 2.5 (\% drop) & $\begin{array}{r}\text { Nitrogen Oxides (\% } \\
\text { drop) }\end{array}$ \\
\hline Delhi & $62 \%$ & $50 \%$ \\
Ahmedabad & $57 \%$ & $32 \%$ \\
Mumbai & $45 \%$ & $60 \%$ \\
Pune & $31 \%$ & $62 \%$ \\
\hline
\end{tabular}

Tabie: Siddhant Kalra. Source: Air Quality COVID Briefing India = GSCC

From the above table taken from www.gscc.org, it is clear from the fact that, 
The above four cities are been compared for the purpose of approximating the drop in percentage level of PM-2.5 and Nitrogen Dioxide (NO2) level and the above table is made covering the

Period ranging

From the second week of March i.e. before lockdown to 6th April 2020 i.e. during lockdown period, Delhi remain on the top, as with the total drop in PM-2.5 level was the highest

Approximating to 62 percent and in Nitrogen Dioxide it reduces to around 50 percent, next comes the Ahmedabad with the total drop in PM-2.5 level of about 57 percent and 32 percent in case of Nitrogen Dioxide, then comes is Mumbai, with a total reduction in PM-2.5 level around 45 percent and on the contrary Nitrogen Dioxide to drop around 60 percent at the end, Pune which has a total drop in PM-2.5 level to around 31 percent and on the other hand Nitrogen Dioxide to reduce at a total of 62 percent stated in www.geospatialworld.net.

Thus the novel corona-virus has affected many lives, but this fact can't be ignored as to the environment has come to almost an end as compared to the past 20 years, thus showing individuals a fresh and healthy environment. This fresh air has to lead to individuals' breadth in fresh and much healthier air, without PM-2.5 particulate, Nitrogen Dioxide (NO2).

The Satellite view has been recorded and compared with the past six years to compare the level of Nitrogen Dioxide (NO2). Thus the view shows the level of cleanliness in the air which has never been before in the past 20 years.

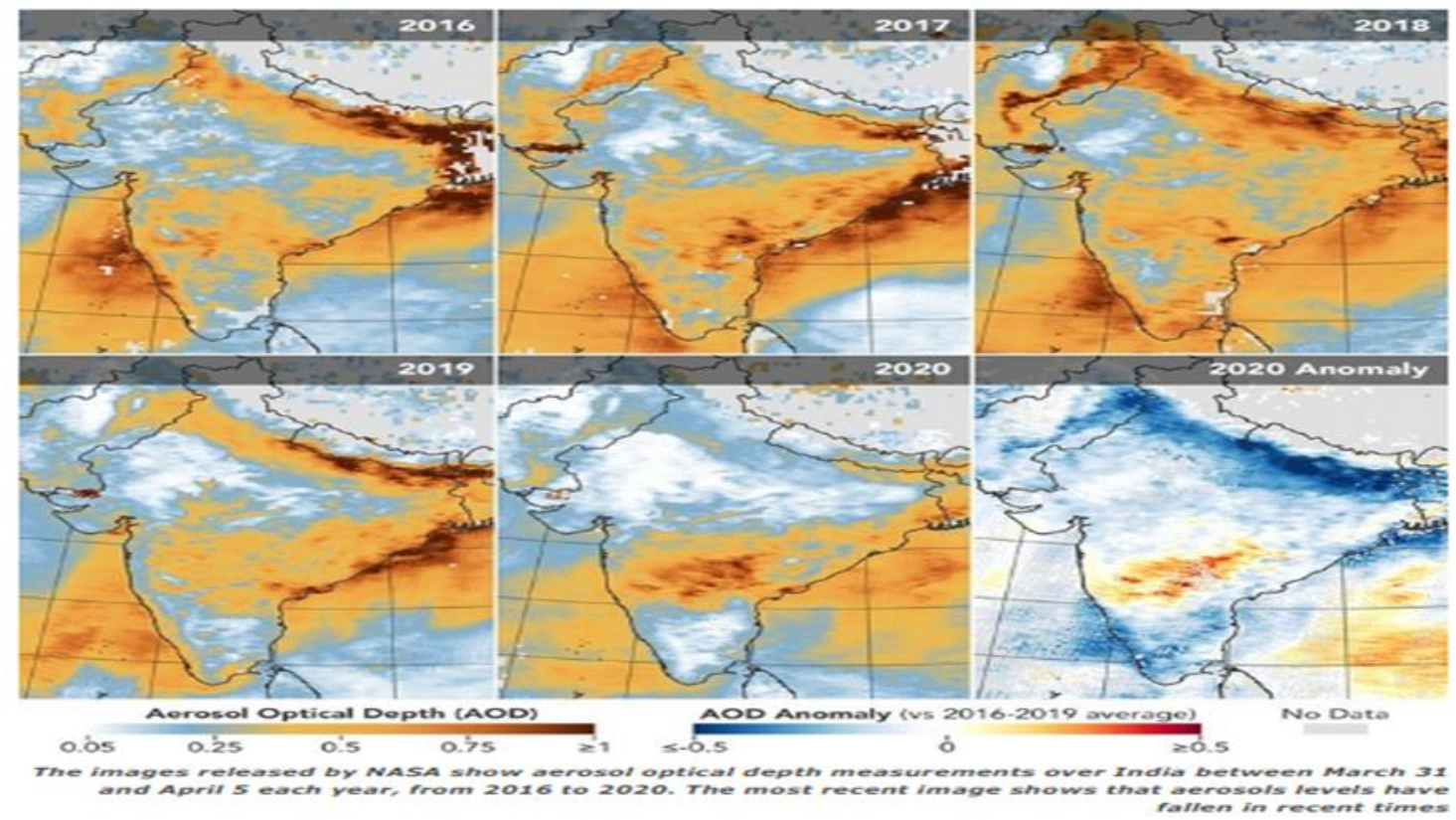

From the above chart showed in www.ntrs.nasa.gov, it is showing the satellite view of India in relation to AOD Aerosol Optical Depth, as in the year 2016 to 2019 it is stating that India was one of the highly polluted countries including Nitrogen Dioxide, aerosols, PM-2.5, PM-10 which shows that this has lead to life expectancy to almost end as more than 3-4 million lives are affected every year, as this air pollution caused due to burning of fossil fuels, from the vehicles which are running in the streets, factories which work in India, Coal and Petroleum industry has affected many lives as stated in www.sciencedirect.com

There has been an increasing trend in the death rate caused due to air pollution in India, but in the year 2020 Anomaly, as in the above diagram it is clear that India seems much clear in terms of air pollution, as with the help of Corona-virus this has lead to put every individual inside their homes, all factories to shut, no working is done during the time of lockdown.

Nitrogen Dioxide (NO2) level comparison before and during lockdown a satellite view, the below four maps of India showing before and after the initial phase of lockdown, showing the reduction in Nitrogen Dioxide across the country : 


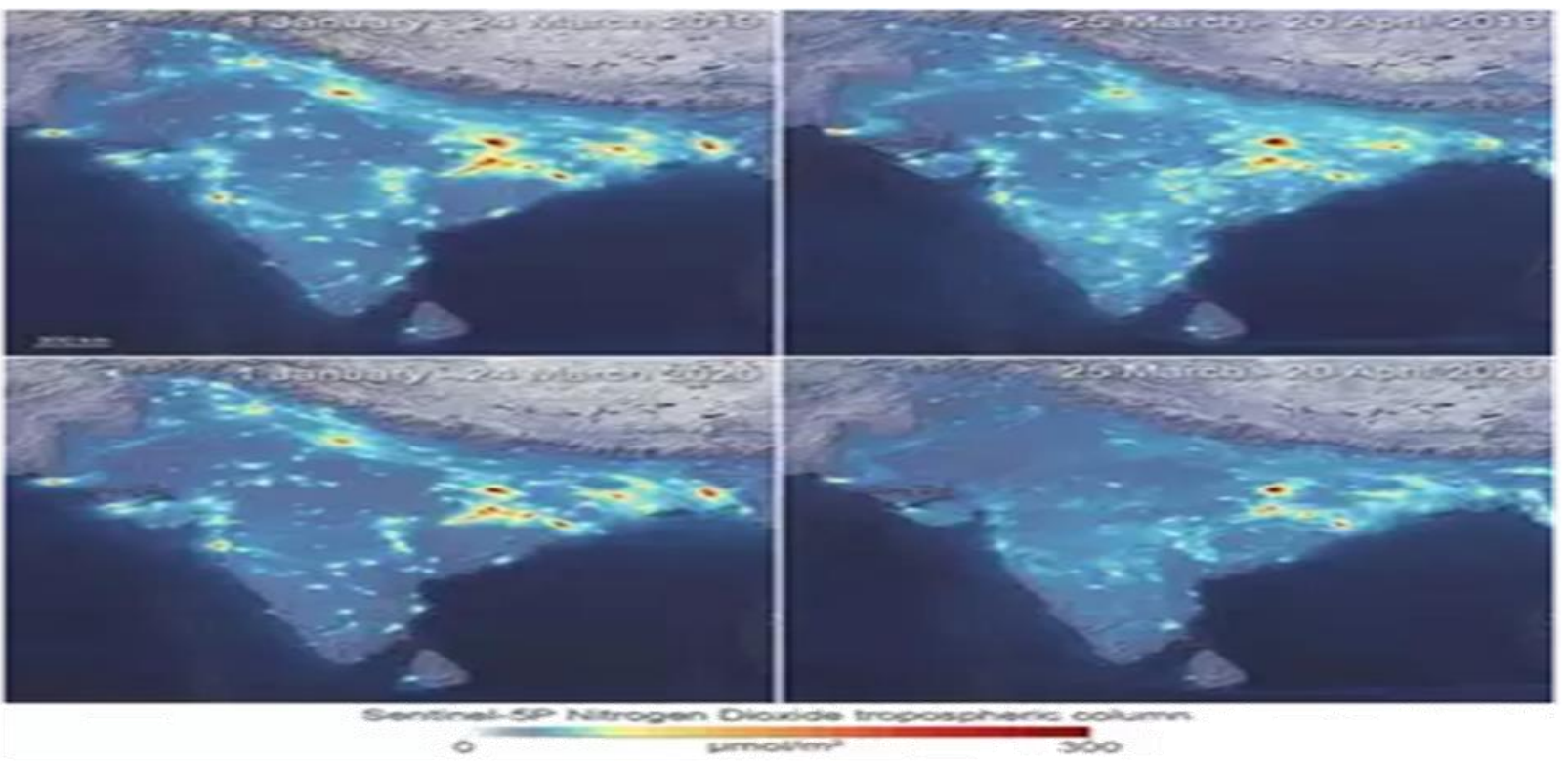

The above two views of the country is been shown before and during the Corona-virus i.e. from 11th march, 2020 to 24th march, 2020 before lock down period, showing that both the cities were affected by the highly with Nitrogen Dioxide (NO2) level as there were proper working being done, all the factories were working, automotives were moving at their pace on the streets, which has caused many lives, But during the time of lockdown i.e. from 25 th march, 2020 to 7th April, 2020, there has been a much cleaner and a much healthier environment seen on the streets, as there was zero movement no production, no vehicle movement, and thus lead to no pollution and showing a much cleaner environment as there is no combustion, no burning of fossil fuels, thus lead to much cleaner environment which has not achieved in the past 20 years. The above view also shows that there has been no change in the environment in East part of India, as remaining of 103 cities i.e. 15 cities are still coming under poor, very poor or even at severe range.

Rise in level of pollution due to relaxation given by state governments in order to start the working, below is the chart showing the increase in level of PM-2.5 and PM-10 as on date 6th May,2020.

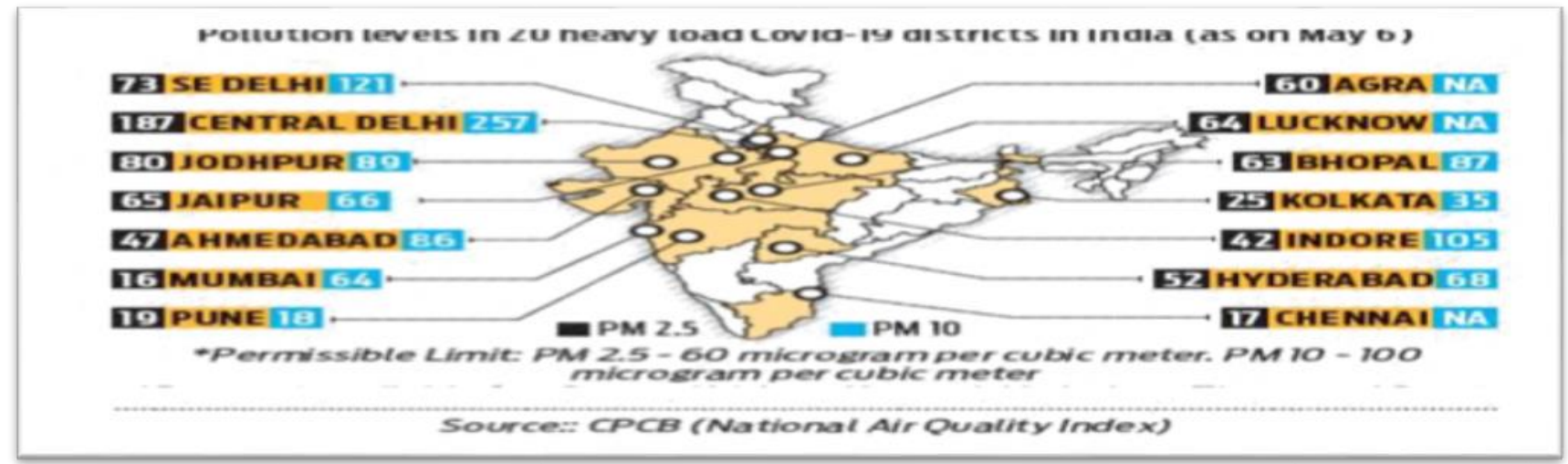

From the above diagram, it is clear from the fact that post lockdown will have a severe impact on the air pollution as not only this the rise in particulate matter in the air will go on increasing and this will lead to various lives in danger, in the above chart it is showing the total of 14 major heavy loaded CoVID-19 districts of India and relating the increase in pollution level with an increase in the number of Corona-virus cases.

The standards set up by WHO as to average level in air quality Index, the permissible limit as to PM-2.5 microgram per cubic particulate matter is 60 and in the case of PM-10 it is 100.

PM10 particles in the air PM10 are very small particles found in dust and smoke. They have a diameter of 10 micrometers $(0.01 \mathrm{~mm})$ or smaller. PM10 particles are a common air pollutant, as stated in www.epa.vic.gov.au 1. The very first district Central Delhi which has seen a sudden rise in pollution level states rise in both PM-2.5 and PM-10 above the permissible limit which is 187 and 257 respectively.

2. The most affected districts are Hyderabad, Indore, Bhopal, and Ahmedabad, etc. all are working over and above the permissible limit set up by the WHO which is for PM-2.5 and PM-10 is 60 and 100 respectively.

3. Without proper rules and regulations, on 7th May 2020 thus contributing to the environment, Vishakhapatnam gas leak in a chemical "Vizag unit of LG polymers" has not taken any precautionary measures and 11 people died 
and more than 1000 people are affected with the poisonous gas in the air, thus contributed to rising in air pollution thus lead to increase in PM-2.5 and PM-10.

4. Boiler tube leakage (blast) at NLC thermal power plant station in Tamil Nadu and has affected the air pollution thus lead to an increase in PM-2.5 and PM-10.

5. Chhattisgarh (Raigarh), as on 7th May 2020 there has been a gas leakage in a paper pill and due to the gas the total of 7 workers affected and was got hospitalized.

\section{Future prospects of Air Pollution in India}

While considering the future prospects, it is easily be stated that what Indian government won't able to achieve from the past twenty years but the Corona-virus pandemic done, but after the Lockdown situation, this won't be same as it was now as stated in www.wefourm.org

As there has been a rise in vehicles been sold in the country which helps in producing air pollution, from the past years there has been a continuous increase in automotive buyers in India, not only this many factories are also been set up in the country which emits harmful gases which are not fit breadth by the humans, thus affecting their lives, depleting ozone level thus making unfit for breadth. The poor quality of air pollution will not only affect the outdoor air but also the indoor air.

If the rise in air pollution should not come to an end or reduced to the set permissible limit as set up by World Health Organization i.e. PM-2.5 and PM-10 with permissible limit 60 and 100, buy the financial year 2030 the Air will be so noxious that for normal breadth one will require an oxygen kit. Some of the harmful consequences of air pollution as stated in www.kent.co.in are:

Put a stop to photosynthesis, which affects the air quality

- Acerbic rain,

- Diminution of the ozone layer

- Global lukewarm

- Cardiovascular infection

- Allergies

- Bronchitis in the midst of kids

- Dawdling pulmonary improvement

Ambient air pollution in India is estimated to cause 670,00 deaths annually and particularly aggravates respiratory and cardiovascular conditions including chronic bronchitis, lung cancer, and asthma as stated in www.wikipedia.org

\section{Conclusion}

From the above paper it is clear from the fact that India has affected a lot from the Corona-virus pandemic as more than 58000 individuals are affected with this pandemic as on 7th May 2020 but this has also affected the environment in a very positive way, with the complete lockdown, India could able to achieve the Air Quality Index (AQI) range from 0 to 100 which wasn't seen in the past 20 years, helps the individual to inhale much healthy and fresh air, the satellite view was also shown as to compare that India can achieve the reliable level of quality in the air. This lockdown has reduced the PM-2.5 and PM-10 levels up to 60-70 percent, not only this approximately around 60 percent drop in Nitrogen Dioxide as well.

\section{References}

1. Bukhari, Q., \& Jameel, Y. (2020). Will Coronavirus Pandemic Diminish by Summer? SSRN Electronic Journal. https://doi.org/10.2139/ssrn.3556998

2. Chay, K. Y., \& Greenstone, M. (2011). Air Quality, Infant Mortality, and the Clean Air Act of 1970. SSRN Electronic Journal, August. https://doi.org/10.2139/ssrn.509182

3. Chen, Y., Ebenstein, A., Greenstone, M., \& Hongbin, L. (2013). Evidence on the Impact of Sustained Exposure to Air Pollution on Life Expectancy from China's Huai River Policy. SSRN Electronic Journal. https://doi.org/10.2139/ssrn.2291154

4. Ismail, S., \& Ahmed, S. (2018). Air Pollution, its Sources and Health Effects : A Case Study of Delhi. 9(4), 62-74.

5. Khot, W. Y., \& Nadkar, M. Y. (2020). The 2019 Novel Coronavirus Outbreak - A Global Threat. The Journal of the Association of Physicians of India, 68(3), 67-71.

6. Leveson, R. C. (1989). Environmental pollution. Indian Journal of Environmental Protection, 9(9), $710-711$.

7. Van Der Hoek, L., Pyrc, K., Jebbink, M. F., Vermeulen-Oost, W., Berkhout, R. J. M., Wolthers, K. C., Wertheim-Van Dillen, P. M. E., Kaandorp, J., Spaargaren, J., \& Berkhout, B. (2004). Identification of a new human coronavirus. Nature Medicine, 10(4), 368-373. https://doi.org/10.1038/nm1024

8. Websites:

9. https://scroll.in/article/961196/air-pollution-will-mean-more-covid-19-deaths-the-warning-is-loudand-clear-for-india

10. https://www.downtoearth.org.in/blog/pollution/lessons-from-covid-19-on-reducing-india-senvironmental-pollution-70891 
11. https://www.geospatialworld.net/blogs/air-pollution-drops-in-india-courtesy-covid-19/

12. https://indianexpress.com/article/opinion/columns/covid-19-pandemic-environment-protectionpollution-amit-sibal-6393959/

13. https://www.ecowatch.com/india-air-pollution-coronavirus-2645617908.html

14. https://www.mygov.in/covid-19

15. https://www.who.int/emergencies/diseases/novel-coronavirus2019? gclid=Cj0KCQjwzN71BRCOARIsAF8pjfghAD6oU8kYLSkWXvWOov_WgMeS26EwhFjP_ 7J8vdJJkwyAzoPLuukaAgV8EALw_wcB

16. https://science.thewire.in/environment/ganga-river-lockdown-cleaner-namami-gange-sewagetreatment-ecological-flow/ 